\title{
Calculation and reliability of timber structure bolt connection subjected to double unequal shears with thick plates as outer members
}

\author{
Josef Musilek ${ }^{1, *}$ and Luboš Podolka ${ }^{1}$ \\ ${ }^{1}$ Institute of Technology and Business in České Budějovice, Department of Civil Engineering, \\ Okružní 517/10, 37001 České Budějovice, Czech Republic
}

\begin{abstract}
The paper shows the calculation and reliability assessment of bolted connections subjected to unequal double shear with thick plates as outer members and inner timber member. This situation can occur very often during the designing of the timber structure bolt connection. Bolted connections subjected to unequal double shear are not described in present European standards where there is described only calculation and reliability of timber structure bolt connection subjected to double equal shears. So structure engineers have no rules which help them during a designing process when they are confronted with this case. The concrete example for the case of unequal shears is calculated and explained.
\end{abstract}

\section{Introduction}

In [1] and [2] and there were derived formulas for determination of design load-carrying capacity and for assessment of reliability in ultimate limit state of bolt connections subjected to unequal double shears with thick plates as outer members and inner timber member. In present there is no method contained in [3] which would give a procedure how to calculate design load-carrying capacity, and the reliability in ultimate limit state of such connection.

\section{Example of connection}

The connection arrangement according to is assumed.

\footnotetext{
*Corresponding author: musilek@mail.vstecb.cz
} 

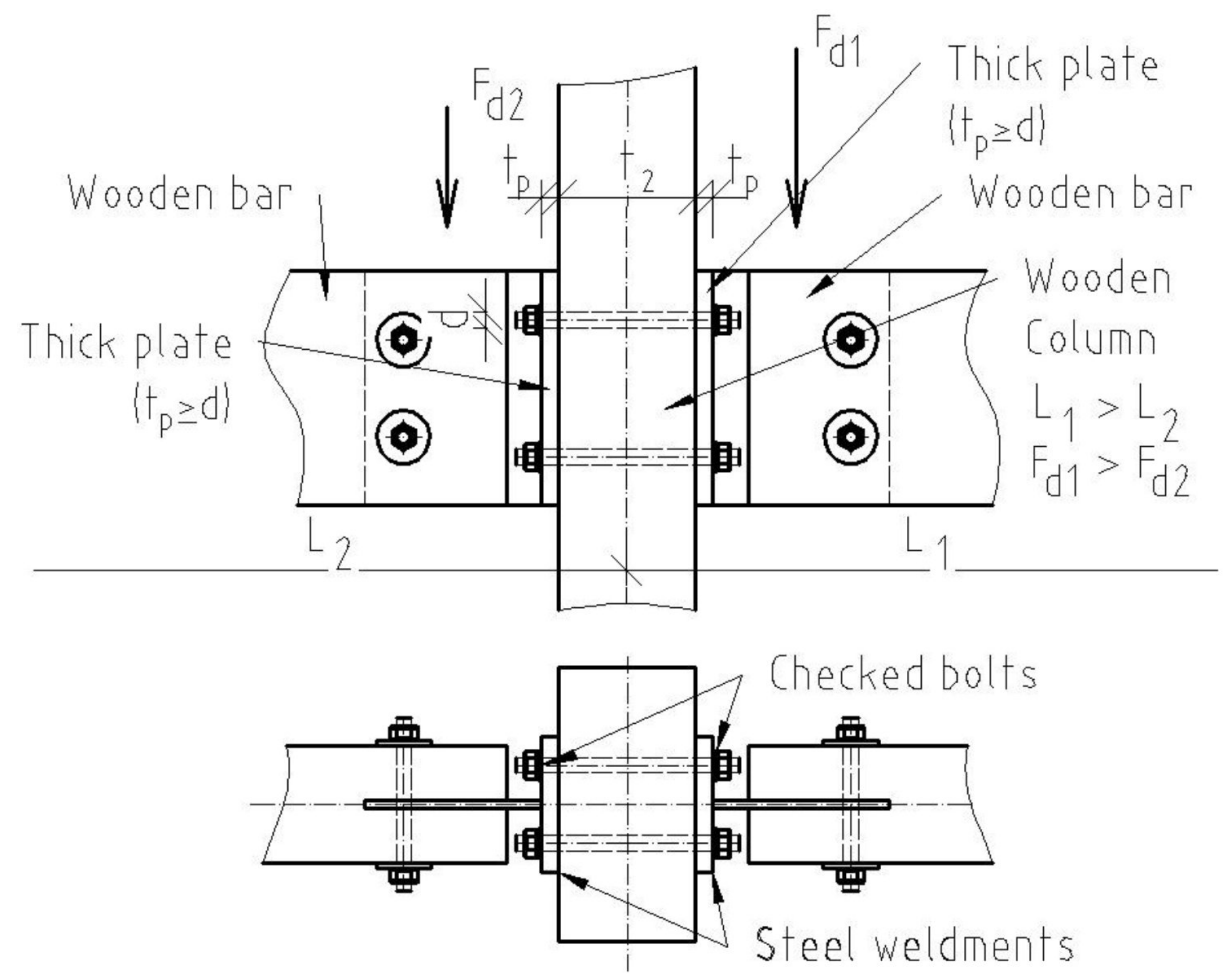

Fig. 1. Connection arrangement.

Fig. 1 presents a connection of wooden bars with a wooden column. The connection between the bars and the column is made by steel elements of $\mathrm{T}$ shape and by bolts. The spans of bars $L_{l}$ and $L_{2}$ are not equal, $L_{1}>L_{2}$ so the design load $F_{d l}$ is bigger than $F_{d 2}$. The loads $F_{d 1}$ and $F_{d 2}$ strain the bolts in girder by shear. The plates at the girder are classified as thick plates, because $t_{p} \geq d$, and it is assumed that the tolerance allowance for the bolt hole is less than $0,1 d$. It is also assumed, that the materials of the connection is not degraded by biological pest for example as it is shown in [4].

In the example, there is only checked the shear resistance of the bolts in the column. These bolts are marked in as "Checked bolts".

The input variables are as follows:

- design loads of the connection: $F_{d 1}=32 \mathrm{kN} ; F_{d 2}=12 \mathrm{kN}$,

- $\quad$ width of the middle timber part: $t_{2}=60 \mathrm{~mm}$,

- material of the middle timber part: $\mathrm{C} 24$,

- $\quad$ apparent density: $\rho_{k}=370 \mathrm{~kg} / \mathrm{m}^{3}$,

- $\quad$ angle between the load directions and the grain of the middle timber part: $\alpha=0^{\circ}$,

- characteristic tensile strenght of the bolt: $f_{u k}=360 \mathrm{MPa}$,

- diameter of the bolts: $d=16 \mathrm{~mm}$,

- tensile bolt area: $A_{s}=157 \mathrm{~mm}^{2}$,

- thickness of the outer steel plates: $t_{\text {plate }}=16 \mathrm{~mm}$,

- modification factor: $k_{\text {mod }}=0,8$,

- $\quad$ partial factor for timber: $\gamma_{M}=1,3$. 
The design load-carrying capacity for different failure modes were derived in [1] and [2]. When we increase the loads in the way that the ratio $n=F_{d 2} / F_{d l}$ stays constant, the following formulas for the design load-carrying capacity are as follows:

Failure mode a) (the member for characteristic withdrawal capacity of the bolt according to [3] is omitted)

$$
R_{d 1}=\frac{k_{m o d}}{\gamma_{M}}\left(2,3 \cdot \sqrt{M_{y, R k} \cdot f_{h, 2, k} \cdot d}\right)
$$

Failure mode b)

$$
R_{d 1}=\frac{k_{m o d}}{\gamma_{M}} \cdot \frac{t_{2} \cdot f_{h, 2, k} \cdot d}{1+n}
$$

Failure mode c)

$$
R_{d 1}=\frac{k_{m o d}}{\gamma_{M}} \cdot f_{h, 2, k} \cdot d \cdot \frac{\sqrt{t_{2}{ }^{2} \cdot 2 \cdot\left(1+n^{2}\right)+(1+n)^{2} \cdot \frac{8 \cdot M_{y k}}{f_{h, 2, k} \cdot d}}+t_{2} \cdot(n-1)}{(1+n)^{2}}
$$

At first we calculate some values needed for further calculation:

Characteristic embedment strength in the hole for the bolt in the girder $f_{h, 2, k}$ :

$$
\begin{gathered}
f_{h, 0, k}=0,082 \cdot(1-0,01 \cdot d) \cdot \rho_{k}=0,082 \cdot(1-0,01 \cdot 16) \cdot 370=25,49 \mathrm{MPa} \\
k_{90}=1,35+0,015 \cdot d=1,35+0,015 \cdot 16=1,59 \\
f_{h, 2, k}=\frac{f_{h, 0, k}}{k_{90} \cdot(\sin \alpha)^{2}+(\cos \alpha)^{2}}=\frac{25,49}{1,59 \cdot(\sin 0)^{2}+(\cos 0)^{2}}=25,49 \mathrm{MPa}
\end{gathered}
$$

Characteristic bolt yield moment

Ratio n:

$$
M_{y, R k}=0,3 \cdot f_{u, k} \cdot d^{2,6}=0,3 \cdot 360 \cdot 16^{2,6}=1,459 \cdot 10^{5} \mathrm{Nmm}
$$

$$
n=\frac{\mathrm{F}_{\mathrm{d} 2}}{\mathrm{~F}_{\mathrm{d} 1}}=\frac{12}{32}=0,375
$$

Design load-carrying capacity for the failure mode a)

$$
\begin{gathered}
R_{d 1}=\frac{k_{\text {mod }}}{\gamma_{M}}\left(2,3 \cdot \sqrt{M_{y, R k} \cdot f_{h, 2, k} \cdot d}\right)=\frac{0,8}{1,3} \cdot\left(2,3 \cdot \sqrt{1,459 \cdot 10^{5} \cdot 25,49 \cdot 16}\right)= \\
=10,92 k N
\end{gathered}
$$

Design load-carrying capacity for the failure mode b) 


$$
R_{d 1}=\frac{k_{m o d}}{\gamma_{M}} \cdot \frac{t_{2} \cdot f_{h, 2, k} \cdot d}{1+n}=\frac{0,8}{1,3} \cdot \frac{60 \cdot 25,49 \cdot 16}{1+0,375}=10,95 \mathrm{kN}
$$

Design load-carrying capacity for the failure mode c)

$$
\begin{aligned}
& R_{d 1}=\frac{k_{m o d}}{\gamma_{M}} \cdot f_{h, 2, k} \cdot d \cdot \frac{\sqrt{t_{2}{ }^{2} \cdot 2 \cdot\left(1+n^{2}\right)+(1+n)^{2} \cdot \frac{8 \cdot M_{y k}}{f_{h, 2, k} \cdot d}}+t_{2} \cdot(n-1)}{(1+n)^{2}} \\
= & \frac{0,8}{1,3} \cdot 25,49 \cdot 16 \\
& \frac{\sqrt{60^{2} \cdot 2 \cdot\left(1+0,375^{2}\right)+(1+0,375)^{2} \cdot \frac{8 \cdot 1,459 \cdot 10^{5}}{25,49 \cdot 16}}+60 \cdot(0,375-1)}{(1+0,375)^{2}} \\
= & 10,52 \mathrm{kN}
\end{aligned}
$$

Resultant design load-carrying capacity:

$$
R_{d}=\min (10,92 k N, 10,95 k N, 10,52 k N)=10,52 \mathrm{kN}
$$

The reliability:

$$
n=\frac{\mathrm{F}_{\mathrm{d} 1}}{4 \cdot \mathrm{R}_{\mathrm{d}}}=\frac{32}{4 \cdot 10,52}=0,760
$$

There is also possibility that the load $F_{d 2}$ remains constant and the load $F_{d l}$ is increasing only. So we can write $R_{d 2}=F_{d 2} / 4$. In [1] and [2] formulas were derived for this case. If we use them for our example, we obtain the following results:

Failure mode a) (the member for characteristic withdrawal capacity of the bolt according to [3] is omitted)

$$
\begin{gathered}
R_{d 1}=\frac{k_{\text {mod }}}{\gamma_{M}}\left(2,3 \cdot \sqrt{M_{y, R k} \cdot f_{h, 2, k} \cdot d}\right)=\frac{0,8}{1,3} \cdot\left(2,3 \cdot \sqrt{1,459 \cdot 10^{5} \cdot 25,49 \cdot 16}\right)= \\
=10,92 k N
\end{gathered}
$$

Failure mode b)

$$
R_{d 1}=\frac{k_{m o d}}{\gamma_{M}} \cdot f_{h, 2, k} \cdot d \cdot t_{2}-R_{d 2}=\frac{0,8}{1,3} \cdot 25,49 \cdot 16 \cdot 60-\frac{12000}{4}=11,47 \mathrm{kN}
$$


Failure mode c)

$$
\begin{aligned}
& R_{d 1}=\frac{k_{\text {mod }}}{\gamma_{M}} \cdot f_{h, 2, k} \cdot d \cdot\left(\sqrt{2 \cdot\left(t_{2}{ }^{2}+\frac{4 \cdot M_{y k}}{f_{h, 2, k} \cdot d}+\frac{2 \cdot \gamma_{M} \cdot R_{d 2} \cdot t_{2}}{k_{m o d} \cdot f_{h, 2, k} \cdot d}\right)}-t_{2}\right)-R_{d 2} \\
& =\frac{0,8}{1,3} \cdot 25,49 \cdot 16 \cdot\left(\sqrt{2 \cdot\left(60^{2}+\frac{4 \cdot 1,459 \cdot 10^{5}}{25,49 \cdot 16}+\frac{2 \cdot 1,3 \cdot \frac{12000}{4} \cdot 60}{0,8 \cdot 25,49 \cdot 16}\right)}-60\right)-\frac{12000}{4} \\
& =10,48 \mathrm{kN}
\end{aligned}
$$

Resultant design load-carrying capacity:

$$
R_{d}=\min (10,92 k N, 11,47 k N, 10,48 k N)=10,48 \mathrm{kN}
$$

The reliability:

$$
n=\frac{\mathrm{F}_{\mathrm{d} 1}}{4 \cdot \mathrm{R}_{\mathrm{d}}}=\frac{32}{4 \cdot 10,48}=0,7
$$

\section{Summary}

The example for reliability assessment of bolt connection of bolted connections subjected to unequal double shear with thick plates as outer members and inner timber member was presented. The two different ways of loading were considered. The differences between these two ways of loading were not significant for the reliability assessment.

\section{References}

1. K. Kubečka, J. Musílek, Contemporary Problems of Architecture and Construction (Univerzita Degli Study Firenze, 7, 59-62, 2015)

2. J. Musílek, J. Žák, 8th International Conference Building Defects (The Institute of Technology and Business in České Budějovice, , České Budějovice, to be published)

3. EN 1995-1-1, Design of timber structures. Part 1-1: General-Common rules and rules for buildings (1995)

4. P. Bednářová, A. Hynková, Littera Scripta (The Institute of Technology and Business in České Budějovice, České Budějovice, 2009) 